\title{
Pemanfaatan karbon aktif dari sabut kelapa sebagai elektroda superkapasitor
}

\author{
Farly Reynol Tumimomor ${ }^{* a}$, Septiany Christin Palilingan ${ }^{b}$
}

almu Fisika FMIPA, Universitas Negeri Manado, Tondano, 95619, Indonesia

bImu Kimia FMIPA, Universitas Negeri Manado, Tondano, 95619, Indonesia

INFO ARTIKEL

Diterima 13 Maret 2018

Disetujui 27 Maret 2018

\section{Key word: \\ Coconut fiber, \\ activated carbon, \\ The specific capacitance, \\ Supercapacitor}

\section{Kata kunci:}

Sabut kelapa

Karbon aktif,

Kapasitansi spesifik,

Superkapasitor.

${ }^{*}$ e-mail:

farlytumimomor@unima.ac.id

${ }^{*}$ Telp:

085289424554

\begin{abstract}
A B S T R A C T
In this study, coconut fiber based activated carbon has been used for fabrication of supercapacitors. Iodine absorption test is performed to measured absorption level porous activated carbon sample size is relatively small (microporous). Characteristics of the activated carbon material covering the surface morphology and structure were tested using SEM and XRD. Electrode materials with composition (Activated charcoal: $P V D F=9: 1(w / w))$, the current collector and separator has been assembled to be tested its performance as an electrical charge storage device. The test results by cyclic voltammetry method was to look at the performance supercapacitor devices at once to obtain the value of the capacitance curve obtained voltammograms. Based on the results of the calculation of the capacitance, the highest capacitance values obtained in the supercapacitor with activated carbon electrodes in coconut fiber steam $50 \mathrm{~mL} /$ bar with a capacitance value is $50.73 \mathrm{~F} / \mathrm{g}$.
\end{abstract}

\section{A B STRAK}

Pada penelitian ini, karbon aktif berbasis sabut kelapa telah digunakan untuk pembuatan superkapasitor. Uji daya jerap iodin dilakukan untuk mengukur tingkat serapan pori sampel karbon aktif yang ukurannya relatif kecil (mikropori). Karakteristik bahan karbon aktif yang meliputi struktur kristal dan morfologi permukaannya diuji dengan menggunakan SEM dan XRD. Bahan elektroda dengan komposisi (Karbon aktif : PVDF = 9:1 (b/b)), kolektor arus dan separator telah dirangkai untuk diuji kinerjanya sebagai perangkat penyimpanan muatan listrik. Metode siklik voltametri digunakan untuk melihat kinerja perangkat superkapasitor dengan mengukur nilai kapasitansi spesifik berdasarkan kurva voltammogram. Berdasarkan hasil perhitungan nilai kapasitansi spesifik diperoleh nilai kapasitansi spesifik tertinggi pada superkapasitor dengan elektroda sabut kelapa yang diaktivasi dengan steam $50 \mathrm{~mL} /$ bar yaitu sebesar $50.73 \mathrm{~F} / \mathrm{g}$.

\section{Pendahuluan}

Penyediaan energi di masa depan merupakan permasalahan yang senantiasa menjadi perhatian semua bangsa karena bagaimanapun juga kesejahteraan manusia dalam kehidupan modern sangat terkait dengan jumlah dan mutu energi yang dimanfaatkan. Bagi Indonesia yang merupakan salah satu negara sedang berkembang, penyediaan energi khususnya energi listrik merupakan faktor yang sangat penting dalam mendorong pembangunan.
Menurut La Ode Muhammad pemakaian energi listrik selama kurun waktu tahun 2000 sampai dengan tahun 2025 diperkirakan meningkat rata-rata $7,1 \%$ per tahun [1].

Energi listrik dapat dihasilkan dari sumber energi terbarukan seperti, matahari dan angin, akan tetapi efektivitas penggunaannya membutuhkan penyimpanan energi listrik yang efisien. Pengembangan dalam sistem penyimpanan energi listrik sangat penting untuk penyamarataan efektivitas alami siklus sumber-sumber energi 
[2].

Baterai dan superkapasitor adalah teknologi sistem penyimpanan energi listrik terkemuka saat ini. Keduanya didasarkan pada mekanisme elektrokimia. Baterai menyimpan energi listrik dalam senyawa kimia yang mampu menghasilkan muatan, sedangkan superkapasitor menyimpan energi listrik secara langsung sebagai muatan [3]. Dingemukakan bahwa dalam beberapa tahun terakhir, superkapasitor sangat menarik perhatian dalam teknologi penyimpanan energi listrik karena memiliki kerapatan energi yang lebih tinggi dibandingkan kapasitor konvensional dan kerapatan daya yang lebih tinggi dibandingkan baterai. Keuntungan lain dari superkapasitor adalah tingkat pengisian yang cepat dan umur siklus pengisian yang Panjang [4].

Salah satu faktor yang mempengaruhi tingkat keefektifan superkapasitor adalah penggunaan bahan elektroda. Karbon aktif adalah salah satu jenis bahan yang secara luas telah digunakan sebagai bahan elektroda untuk superkapasitor karena memiliki luas permukaan spesifik yang tinggi, ketahanan kimia, konduktivitas listrik yang baik dan harga yang terjangkau [5]; [6]; [7]. Sabut kelapa dapat dijadikan sumber bahan baku dalam pembuatan karbon aktif. Kandungan karbon dalam selulosa yang terdapat pada sabut kelapa, menjadikan bahan ini dapat dijadikan alternatif dalam pembuatan karbon aktif.

Pada penelitian ini, telah dibuat dan dikarakterisasi superkapasitor menggunakan bahan karbon aktif berbasis sabut kelapa sebagai elektroda dengan aktivator $\mathrm{KOH}$ dan variasi laju aliran uap air dalam proses aktivasi untuk menghasilkan perangkat penyimpanan energi listrik dan pada akhirnya menghasilkan teknologi sistem penyimpanan energi listrik yang ekonomis.

\section{Bahan dan Metode}

Bahan yang digunakan dalam penelitian

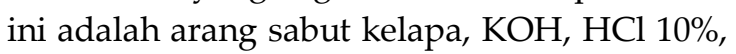
akuades, $\mathrm{pH}$ indikator, PVDF $10 \%$, larutan NMP, larutan elektrolit $\mathrm{H}_{2} \mathrm{SO}_{4} 1 \mathrm{M}$, larutan $\mathrm{AgNO}_{3}$ 0,1 M, membran PTFE, plastik acrylic, stainless stell 100 mesh.

\section{Proses aktivasi sabut kelapa}

Tahap pertama adalah pembentukan arang sabut kelapa melalui proses karbonisasi pada suhu $400^{\circ} \mathrm{C}$ selama 4 jam, selanjutnya mencampur $\mathrm{KOH}$ dan arang dengan perbandingan massa 3:1. Campuran ini dibiarkan selama 24 jam untuk menjamin keberlangsungan proses difusi ke bagian dalam pori arang. Tahap selanjutnya campuran dijemur sampai kering. Serbuk arang yang sudah dicampur tersebut diaktivasi pada suhu $800^{\circ}$ selama 60 menit (Aripin dkk. 2010) dengan variasi laju uap air (steam) $25 \mathrm{~mL} / \mathrm{bar}$ dan 50 $\mathrm{mL} /$ bar. Tahap terakhir adalah pencucian arang dengan $\mathrm{HCl}$ dan aquades untuk membuang senyawa garam alkali. Karbon aktif selanjutnya dikeringkan pada suhu $100^{\circ} \mathrm{C}$ selama 24 jam untuk mengeluarkan uap air yang terjebak di dalam pori.

\section{Uji daya jerap iodin}

Karbon aktif ditimbang sebanyak 0,25 gram, kemudian dilarutkan dalam $25 \mathrm{~mL}$ larutan iodin 0,1 $\mathrm{N}$ dalam labu Erlenmeyer. Labu Erlenmeyer tersebut selanjutnya digoyang selama 15 menit, kemudian disaring dengan kertas saring. Larutan iodin hasil saringan tersebut diambil sebanyak $10 \mathrm{~mL}$ dititrasi dengan larutan $\mathrm{Na}_{2} \mathrm{~S}_{2} \mathrm{O}_{3}, 0,1 \mathrm{~N}$ sampai warna larutan menjadi bening. Perlakuan titrasi tersebut dilakukan sebanyak 2 kali (duplo).

\section{Uji konduktivitas}

Karbon aktif ditimbang sebanyak 0,3 gram, kemudian dimasukkan ke dalam tabung silinder berdiameter $1,51 \mathrm{~cm}$ dan panjang \pm 10 $\mathrm{cm}$. Karbon aktif yang telah dimasukkan dalam tabung ditutup dengan cara ditekan dengan penutup tabung hingga tertutup rapat. Setelah itu tabung silinder yang telah berisi arang tersebut diuji konduktivitasnya dengan menggunakan LCR meter.

\section{Pembuatan elektroda karbon aktif}

Karbon aktif dikeringkan pada suhu $100^{\circ} \mathrm{C}$ dalam oven selama 1 jam untuk menghilangkan uap air. Setelah itu didinginkan dalam desikator selama 15 menit. Selanjutnya dibuat campuran karbon aktif dengan PVDF (polyvinylidene flouride) sebanyak 
0,5 gram, dengan perbandingan karbon aktif : PVDF (9:1 (b/b)). Kemudian campuran tersebut ditambahkan larutan NMP (pyrrolidinone) hingga membentuk gel, sambil diaduk selama 15 menit. Setelah itu gel yang terbentuk tersebut dioles diatas permukaan stainless steel 100 mesh, dan dikeringkan di dalam oven pada suhu $100^{\circ} \mathrm{C}$ selama \pm 24 jam.

\section{Pembuatan superkapasitor}

Dua elektroda karbon aktif ditimbang. Selanjutnya masing-masing elektroda tersebut beserta separator dibasahi dengan larutan elektrolit $\mathrm{H}_{2} \mathrm{SO}_{4} 1 \mathrm{M}$. Selanjutnya dua buah elektroda karbon aktif dan separator yang telah dibasahi $\mathrm{H}_{2} \mathrm{SO}_{4}$ disusun, dimana separator berada di antara kedua elektroda dan ketiga susunan tersebut dimampatkan dengan menggunakan plastik akrilik dan sekrup.

\section{Hasil dan Pembahasan}

\section{Daya jerap iodin dan konduktivitas}

Uji daya jerap iodin dilakukan untuk mengukur tingkat serapan pori yang ukurannya relatif kecil (mikropori). Hasil pengujian daya jerap iodin menunjukkan bahwa daya jerap iodin karbon aktif sabut kelapa dengan steam $25 \mathrm{~mL} /$ bar memiliki nilai yang lebih tinggi yaitu 839,01 $\mathrm{mg} / \mathrm{g}$ dibandingkan sabut kelapa dengan steam 50 $\mathrm{mL} /$ bar yaitu $761,87 \mathrm{~mL} /$ bar (Tabel 1). Hal ini disebabkan karena dengan penambahan steam menyebabkan sejumlah pori dalam karbon aktif menjadi lebih besar, sehingga nilai uji daya jerap iodin untuk karbon aktif sabut kelapa dengan steam $25 \mathrm{~mL} / \mathrm{bar}$ relatif lebih kecil dibandingkan dengan steam $50 \mathrm{~mL} /$ bar.

Tabel 1. Uji daya iodin dan konduktivitas sabut kelapa

\begin{tabular}{lll}
\hline Sampel & $\begin{array}{c}\text { Daya jerap } \\
\text { iodin } \\
(\mathrm{mg} / \mathrm{g})\end{array}$ & $\begin{array}{c}\text { Konduktivitas } \\
(\mathrm{S} / \mathrm{m})\end{array}$ \\
\hline Kontrol & 703,87 & 44,03 \\
Steam 25 & 839,01 & 108,95 \\
Steam 50 & 761,87 & 125,78 \\
\hline
\end{tabular}

Ketika dibandingkan dengan kontrol (arang tanpa perlakuan penambahan $\mathrm{KOH}$ dan steam) didapatkan bahwa arang yang telah diaktivasi dengan $\mathrm{KOH}$ dan steam $25 \mathrm{~mL} / \mathrm{bar}$, menunjukkan nilai daya jerap iodin yang cenderung lebih besar. Hal ini disebabkan dengan meningkatnya rasio penambahan $\mathrm{KOH}$ dapat menyebabkan peningkatan porositas [5, $7,8]$.

Hasil pengukuran konduktivitas menunjukkan bahwa nilai konduktivitas dari karbon aktif cenderung makin besar seiring dengan peningkatan steam yaitu sebesar 108,95 $\mathrm{S} / \mathrm{m}$ untuk karbon aktif sabut kelapa dengan steam $25 \mathrm{~mL} /$ bar dan 125,78 S/m untuk karbon aktif sabut kelapa dengan steam $50 \mathrm{~mL} / \mathrm{bar}$. Faktor yang membuat konduktivitas karbon aktif dengan steam $50 \mathrm{~mL} / \mathrm{bar}$ lebih besar dari steam $25 \mathrm{~mL} / \mathrm{bar}$ karena adanya perbedaan kerapatan dan resistansi (hambatan) antara kedua sampel, dimana karbon aktif dengan steam $25 \mathrm{~mL} /$ bar memiliki kerapatan dan resistansi yang lebih besar dibandingkan dengan steam $50 \mathrm{~mL} /$ bar . Hal ini sejalan dengan teori yang menyatakan bahwa nilai konduktivitas suatu bahan akan berbanding terbalik dengan kerapatan dan resistansinya.

\section{Morfologi karbon aktif}

Morfologi karbon aktif sabut kelapa dengan steam $25 \mathrm{~mL} / \mathrm{bar}$ dan steam $50 \mathrm{~mL} / \mathrm{bar}$, dapat diamati dengan sistem Scanning Electron Microscopy (SEM). SEM dapat memberikan gambaran mendetail mengenai morfologi permukaan, yaitu spesifik pada partikel karbon dan pori pada karbon aktif. Gambar 1 menunjukkan hasil SEM pada karbon aktif sabut kelapa dengan perlakuan steam 25 $\mathrm{mL} / \mathrm{bar}$ dan $50 \mathrm{~mL} / \mathrm{bar}$ dengan perbesaran hingga 1000 kali. Perlakuan aktivasi mengakibatkan terbentuknya pori pada permukaan karbon aktif. Perlakuan steam 25 $\mathrm{mL} /$ bar dan $50 \mathrm{~mL} /$ bar pada proses aktivasi sampel karbon aktif menyebabkan terbentuknya perbedaan struktur pori pada permukaan karbon aktif. Dari Gambar 1 tampak bahwa struktur pori pada permukaan karbon aktif sabut kelapa steam $50 \mathrm{~mL} / \mathrm{bar}$ memiliki struktur pori dengan distribusi yang lebih seragam, teratur dan smooth juga cenderung memiliki ukuran pori yang lebih besar dibandingkan arang sabut kelapa dengan steam $25 \mathrm{~mL} / \mathrm{bar}$. Hal ini diduga dapat disebabkan karena perlakuan steam yang lebih 
besar hingga 2 kali lipat sehingga dapat menyebabkan terbentuknya ukuran pori yang lebih besar dan distribusi yang lebih merata.

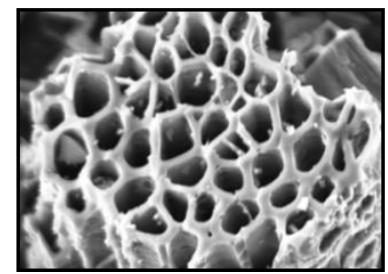

Sabut kelapa steam 25

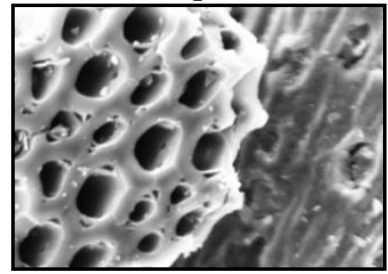

Sabut kelapa steam 50

Gambar 1. Citra sem karbon aktif (a) Sabut kelapa dengan steam 25 dan (b) Sabut kelapa dengan steam 50

\section{Struktur karbon aktif}

Gambar 2 menunjukkan pola difraksi sinar-X (XRD) karbon aktif sabut kelapa.

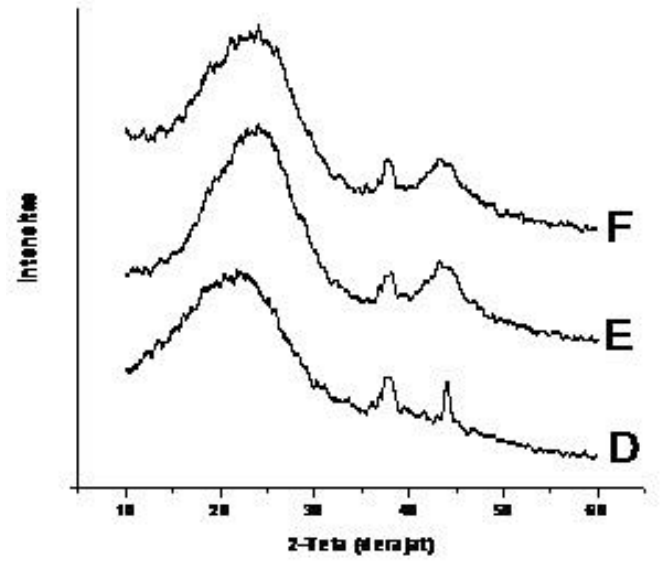

Gambar 2. Difraktogram XRD karbon aktif (a) sabut kontrol; (b) sabut steam 25; (c) sabut steam 50

Pola difraksi yang ditunjukkan melalui difraktogram XRD pada Gambar 2, mengindikasikan bahwa sampel karbon aktif yang digunakan dalam penelitian ini berbentuk grafit, amorf, dan tersusun dari atom-atom karbon. Hal tersebut sejalan dengan hasil penelitian yang dilakukan oleh Pari dkk. dengan menggunakan sampel karbon aktif dari serbuk sengon [9]. Setelah diketahui bentuk dan struktur sampel karbon aktif dengan mengidentifikasi pola difraksinya, maka dapat ditelusuri lebih lanjut mengenai tinggi lapisan $(\mathrm{Lc})$, lebar lapisan (La), jumlah lapisan $(\mathrm{N})$ dan jarak antar lapisan (d) dari sampel karbon aktif tersebut, yang dirangkum pada Tabel 2.

Tabel 2. Tinggi (lc), lebar (la), jarak antar lapisan (d) dan jumlah (n) lapisan aromatik dari karbon aktif sabut kelapa

\begin{tabular}{ccccc}
\hline Sampel & $\begin{array}{c}\mathrm{d} \\
(\mathrm{nm})\end{array}$ & $\begin{array}{c}\mathrm{Lc} \\
(\mathrm{nm})\end{array}$ & $\begin{array}{c}\mathrm{La} \\
(\mathrm{nm})\end{array}$ & $\mathrm{N}$ \\
\hline Kontrol & 0,37 & 8,41 & 70,42 & 22,67 \\
$\begin{array}{c}\text { Steam } \\
25\end{array}$ & 0,37 & 8,41 & 73,36 & 22,67 \\
$\begin{array}{c}\text { Steam } \\
50\end{array}$ & 0,37 & 7,25 & 77,24 & 19,55 \\
50 & & & &
\end{tabular}

Perlakuan steam $(25 \mathrm{~mL} / \mathrm{bar}$ dan 50 $\mathrm{mL} /$ bar) menyebabkan tinggi lapisan (Lc) antar susunan aromatik pada sampel sabut kelapa cenderung semakin menurun. Hal ini menggambarkan ikatan atom antar karbon menyempit sehingga memperpendek jarak atom antar karbon yang berakibat memperkecil nilai Lc.

Begitu juga dengan jumlah lapisan aromatik $(\mathrm{N})$ yang cenderung semakin kecil dengan meningkatnya perlakuan steam, sementara jarak antar lapisan aromatik (d) relatif tetap. Namun, lebar lapisan (La) mengalami peningkatan dengan meningkatnya perlakuan steam.

\section{Kapasitansi spesifik}

Variasi laju scan untuk masing-masing sampel dilakukan untuk mendapatkan nilai kapasitansi tertinggi. Berdasarkan hasil pengukuran untuk masing-masing sampel diperoleh hasil seperti terlihat pada Gambar 3. Hasil pengukuran dengan metode siklik voltametri menunjukkan kurva yang hampir menyerupai empat persegi panjang. Hal ini sesuai dengan hasil yang dikemukakan oleh $\mathrm{Ra}$ dkk yang menyatakan bahwa bentuk kurva untuk superkapasitor yang berbahan dasar karbon adalah berupa empat persegi Panjang [10]. 


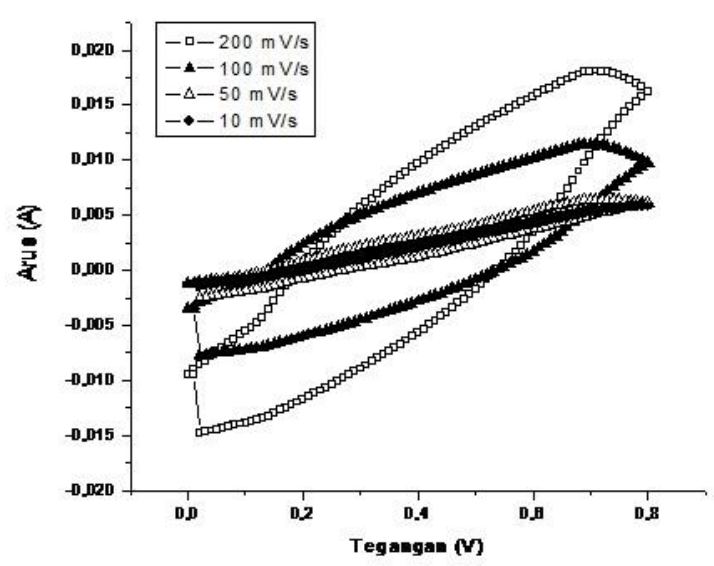

Sabut kelapa steam 25

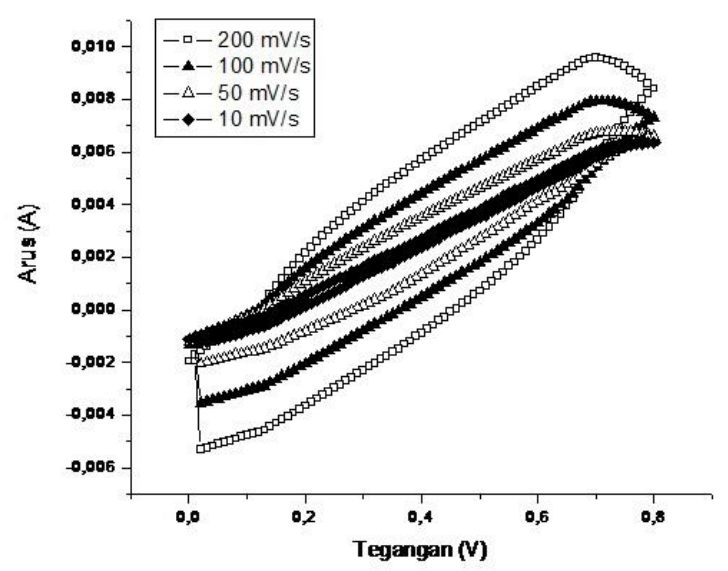

Sabut kelapa steam 50

Gambar 3. Variasi laju scan superkapasitor berbasis bambu dengan variasi steam

Hasil variasi laju scan pada masingmasing sampel (steam 25 dan 50) menunjukkan bahwa semakin rendah nilai laju scan luas daerah yang ditunjukkan semakin kecil, dimana luas daerah yang terkecil yaitu pada laju scan $10 \mathrm{mV} / \mathrm{s}$. Hal ini karena arus yang dihasilkan pada laju scan $10 \mathrm{mV} / \mathrm{s}$ lebih rendah dibandingkan dengan laju scan $50 \mathrm{mV} / \mathrm{s}, 100$ $\mathrm{mV} / \mathrm{s}$, dan $200 \mathrm{mV} / \mathrm{s}$.

Tingkat kemiringan kurva pada Gambar 2 menunjukkan resistansi internal pada tiap laju scan, dimana tingkat kemiringan yang tertinggi dapat dilihat pada laju scan $200 \mathrm{mV} / \mathrm{s}$ yang berarti bahwa resistansi internal tertinggi yaitu pada laju scan $200 \mathrm{mV} / \mathrm{s}$. Hal ini menyebabkan resistansi ohmik untuk pergerakan ion dalam elektrolit semakin besar, sehingga pembentukan lapisan ganda antara elektroda dan ion elektrolit menjadi terbatas yang menyebabkan nilai kapasitansi semakin kecil [11]. Kemiringan kurva siklik voltametri yang terendah yaitu pada laju scan $10 \mathrm{mV} / \mathrm{s}$ yang berarti resistansi internal terendah terdapat pada laju scan $10 \mathrm{mV} / \mathrm{s}$ untuk masing-masing sampel. Hal ini menunjukkan kemampuan paling tinggi superkapasitor dalam menyimpan muatan [12, 13]. Hasil perhitungan nilai kapasitansi untuk masing-masing sampel pada variasi laju scan dapat dilihat pada Gambar 3.

Berdasarkan Tabel 3, tampak bahwa nilai kapasitansi spesifik yang dimiliki oleh superkapasitor dengan elektroda sabut pada steam $50 \mathrm{~mL} / \mathrm{bar}$ lebih tinggi yaitu sebesar 50,73 F/g dibandingkan superkapasitor elektroda bambu dengan steam $25 \mathrm{~mL} /$ bar yaitu sebesar 44,30 F/g. Tingginya nilai kapasitansi spesifik pada superkapasitor elektroda sabut dengan steam $50 \mathrm{~mL} / \mathrm{bar}$ diduga terkait dengan konduktivitas yang dimilikinya lebih tinggi dibandingkan dengan konduktivitas yang dimiliki oleh elektroda sabut dengan steam 25 $\mathrm{mL} / \mathrm{bar}$ (Tabel 1). Selain itu peningkatan steam diduga dapat memperbesar pori karbon aktif sabut kelapa yang menyebabkan distribusi ion elektrolit yang lebih banyak untuk pembentukan lapisan ganda antara elektroda dan ion sehingga menyebabkan nilai kapasitansi spesifik semakin meningkat [14, 15].

Tabel 3. Perbandingan nilai kapasitansi elektroda sabut kelapa

\begin{tabular}{cc}
\hline Sampel & Kapasitansi (F/g) \\
\hline Steam 25 & 44,30 \\
Steam 50 & 50,73 \\
\hline
\end{tabular}

\section{Kesimpulan}

Karbon aktif berbasis bambu sebagai elektroda superkapasitor berhasil dibuat. Berdasarkan hasil penelitian, nilai kapasitansi spesifik tertinggi dimilik oleh superkapasitor dengan elektroda karbon aktif bambu pada aktivasi steam 50 yaitu 59,50 F/g. Hal ini menunjukkan bahwa karbon aktif berbasis bambu layak untuk dimanfaatkan sebagai bahan baku pembuatan elektroda superkapasitor. 


\section{Daftar Pustaka}

1. Wahid, L. O. M. A., Sensitivitas Analisis Potensi Produksi Pembangkit Listrik Renewable Untuk Penyediaan Listrik Indonesia. In Strategi Penyediaan Listrik Nasional Dalam Rangka Mengantisipasi Pemanfaatan PLTU Batubara Skala Kecil, PLTN, Dan Energi Terbarukan., Pusat Pengkajian dan Penerapan Teknologi Konversi dan Konservasi Energi BPPT: Jakarta, 2005; pp 13-22.

2. $\mathrm{Hu}, \mathrm{C}$. Fluid coke derived activated carbon as electrode material for electrochemical double layer capacitor. University of Toronto, 2008.

3. Li, Y.; Van Zijll, M.; Chiang, S.; Pan, N., $\mathrm{KOH}$ modified graphene nanosheets for supercapacitor electrodes. Journal of Power Sources 2011, 196, (14), 6003-6006.

4. Zuleta, M.; Björnbom, P.; Lundblad, A., Effects of pore surface oxidation on electrochemical and mass-transport properties of nanoporous carbon. Journal of The Electrochemical Society 2005, 152, (2), A270-A276.

5. Babel, K.; Jurewicz, K., $\mathrm{KOH}$ activated carbon fabrics as supercapacitor material. Journal of Physics and Chemistry of Solids 2004, 65, (2-3), 275-280.

6. Fellman, B. A.; Atieh, M.; Wang, E. N. In Carbon-based electric double layer capacitors for water desalination, ASME 2010 8th International Conference on Nanochannels, Microchannels, and Minichannels collocated with 3rd Joint US-European Fluids Engineering Summer Meeting, 2010; American Society of Mechanical Engineers: pp 275279.

7. Aripin, H.; Lestari, L.; Ismail, D.; Sabchevski, S., Sago waste based activated carbon film as an electrode material for electric double layer capacitor. Open Materials Science Journal 2010, 4, 117-124.

8. Kierzek, K.; Frackowiak, E.; Lota, G.; Gryglewicz, G.; Machnikowski, J., Electrochemical capacitors based on highly porous carbons prepared by $\mathrm{KOH}$ activation. Electrochimica Acta 2004, 49, (4), 515-523.
9. Pari, G.; Sofyan, K.; Syafii, W.; Buchari, B., Pengaruh lama aktivasi terhadap struktur kimia dan mutu arang aktif serbuk gergaji sengon. Jurnal Penelitian Hasil Hutan 2005, 23, (3), 207-218.

10. Ra, E.; Raymundo-Piñero, E.; Lee, Y.; Béguin, F., High power supercapacitors using polyacrylonitrile-based carbon nanofiber paper. Carbon 2009, 47, (13), 2984-2992.

11. Liu, H.-Y.; Wang, K.-P.; Teng, H., A simplified preparation of mesoporous carbon and the examination of the carbon accessibility for electric double layer formation. Carbon 2005, 43, (3), 559566.

12. Yang, C.-C.; Hsu, S.-T.; Chien, W.-C., All solid-state electric double-layer capacitors based on alkaline polyvinyl alcohol polymer electrolytes. Journal of power sources 2005, 152, 303-310.

13. Xing, W.; Qiao, S.; Ding, R.; Li, F.; Lu, G.; Yan, Z.; Cheng, H., Superior electric double layer capacitors using ordered mesoporous carbons. Carbon 2006, 44, (2), 216-224.

14. Qu, D.; Shi, H., Studies of activated carbons used in double-layer capacitors. Journal of Power Sources 1998, 74, (1), 99107.

15. Wang, X.-F.; Ruan, D.-B.; Wang, D.-Z.; Liang, J., Hybrid electrochemical supercapacitors based on polyaniline and activated carbon electrodes. Acta Physico-Chimica Sinica 2005, 21, (3), 261266. 